\title{
The quantum consciousness model and the theology of the Urantia book
}

\author{
Raul Valverde*
}

\section{Introduction}

The trend to explain consciousness by applying quantum theories has gained popularity in recent years and, although clearly disdained by neuroscientists, more and more researchers direct their steps this way up. Brian D. Josephson (1962) of the University of Cambridge, winner of the 1973 Nobel Prize in Physics for his studies on the quantum effects in superconductors (Josephson effect), proposes a unified field theory of quantum nature that would explain not only consciousness and its attributes, but also all the phenomenology observed to date in terms of parapsychological, metaphysical and mystical experiences (Valverde, 2015b). The Urantia book is a spiritual and philosophical revelation from the spiritual world that aims to unite religion, science and philosophy. The book supports the idea of a unified quantum field and explains the nature of reality by using quantum principles.

In this article, a literature review that supports that quantum nature of consciousness is presented followed by a set of experiments that support the quantum consciousness paradigm. A quantum consciousness model with seven principles is proposed and a table with Urantia book's references that support these statements is presented with explanations on how these references support the model.

\section{Literature review}

$\mathrm{Hu}$ and $\mathrm{Wu}$ (2010) as part of their explanation of the quantum consciousness model, come to the conclusion that materialistic theories for the explanation of consciousness are likely invalid and that quantum effects play important roles in consciousness. Another character that has stood in defense of a quantum theory of consciousness was the physicist Roger Penrose (1994). Penrose (1994) attacks and almost ridicules those who argue that the artificial intelligence of computers can reproduce human attributes, including consciousness. Penrose, based on the mathematical theorem of Gödel and based on subsequent his elaborations, concludes that no system that is deterministic, that is, which is based on rules and deductions, can explain the creative powers of the mind and its judgment. This nullifies the claim of classic physics, computer, neurobiology, etc., that structure themselves into a complex phenomenon of consciousness. Penrose says that only the peculiar characteristics of non-deterministic quantum physics could issue an approximate judgment on consciousness, within a theory that involves quantum phenomena, macro physical and conditions of non-locality. At this point, perhaps it would be interesting to clarify that local conditions are not known in quantum physics, those capabilities that either have a quantum system, experience instant communication between two parts without there being time duration between communication of an event from one point to another system.

\section{Corresponding author: Raul Valverde}

Address: Concordia University,John Molson Building, Canada.

Phone: + + (514) 848-2424 ext. 2968

e-mail $\bowtie$ raul.valverde@concordia.ca

Relevant conflicts of interest/financial disclosures: The authors declare that the research was conducted in the absence of any commercial or financial relationships that could be construed as a potential conflict of interest.

Received: 19 November 2017; Accepted: 18 August 2018 
There is still another favorable group to this explanatory theory of consciousness, which is headed by Dr. Ian N. Marshall (Marshall and Zohar, 1997) who through empirical testing system claims to have the key to the issue. Marshall and Zohar (1997) showed that conscious thought emerges from quantum effects. Quantum physics helped to have a quantum understanding of consciousness. What we are able to perceive with our five senses is not reality. Quantum physics has shown that space and time are illusions of perception. Our body cannot really be a reality if it does not occupy most of the space it seems to occupy; an experiment made at the University of Manchester revealed the shape of the interior of an atom is almost entirely empty space. The question then became how we could possibly make the world around us see us if this is the case (Russell et al., 1993).

The quantum consciousness model suggests that consciousness lives in the quantum domain outside time-space. Fred Wolf (1984) states that there has never been an adequate definition, a clear metaphor, or even a good physical picture of what time is, in quantum mechanics, time is not an observable phenomenon; it is only an extraneous ordering parameter. Davies (1988) indicates that time exists merely as a parameter for gauging the interval between events. Griffin (1986) states that the notion that physics is in some fundamental sense 'timeless' has been widely accepted. Wolf (1984) states that In quantum mechanics, space is an observable. To observe space, we need the observer and the observed. Their separation is 'space.'

$\mathrm{Hu}$ and $\mathrm{Wu}$ (2013) based on their theoretical and experimental studies have shown that: (1) human Consciousness is non-spatial and non-temporal and not in the brain but in prespacetime; (2) brain is an interface between human Consciousness and the external world; $\mathrm{Hu}$ and $\mathrm{Wu}$ (2010) elaborate that the quantum consciousness model includes that quantum effects play important roles in brain and in consciousness such as in wave function collapse. They also explain that consciousness is likely outside spacetime and is the foundation of reality and that conscious intentions likely have physical effects on matter.

The quantum consciousness model proposes that our true consciousness does not exist in our brains or in our bodies, but this illusion of our individual bodies along with the misinformation of our true origins has manifested the idea that we all think independently from one another. With this understanding, it seems possible to scientifically explain telepathy, clairvoyance, spiritual mediums related to the transfer of information between sources without physical means of communication phenomena. When we understand that there is a common spiritual bond between all things in the universe and that we are all part of a divine intelligence, this simple understanding will fill all the holes in modern religions and predictions about the future and literally every occurrence of events (Russell et al., 1993). Unity of Mind is likely achieved through quantum entanglement beyond the current forms of quantum mechanics ( $\mathrm{Hu}$ and $\mathrm{Wu}, 2010$ ). The quantum consciousness paradigm through the principle of entanglement also proposes that although each person appears as a separate and independent, in reality we are all connected to the patterns of universal intelligence also called the absolute. Our body is part of a universal body, our minds are part of the universal mind and in turn all of these are part of the universe (Valverde, 2016).

According to quantum physics, the physical world and its reality, it's just a recreation of the observed. Consciousness likely play important roles in quantum effects such as in wave function collapse that is responsible for the creation of our reality $\mathrm{CHu}$ and $\mathrm{Wu} 2010$ ). We created the body and reality, as we create the experience of our world in its different manifestations dimensional. In its essential state (atomic or cosmic subquantum micro), the body is made of energy and information, not solid matter, this is only a meager level of perception, this is energy and information arising from the endless fields of energy and information spanning the entire universal creation (Valverde 2015a).

The quantum consciousness model also teaches that our true consciousness lives in a constant present and it is not bound by time past and future. Consider the distinction of past, present, and future, what we are conscious of as now is already past, even if only by a fraction of a second. The conscious content of the moment is therefore of that which is past and gone. The future is not yet. The present is but it cannot be specified in words or thoughts, without its slipping into the past. When a future moment comes a similar situation will prevail. Therefore, from the past of the present we may be able to predict, at most, the past of the future. The actual immediate present is always the unknown. 
Wolf (1984) writes that "The closest we come to observing time is observing what Buddhists call 'being-time.' Everything that is, is, was and will be. Every moment remains motionless and frozen. Past, present and future represent a map for the perusal of the all-seeing being-time.". David Bohm writes that atomic structure dissolves into electrons, protons, neutrons, quarks, subquarks, etc., and eventually into dynamically changing forms in an all-pervasive and universal set of fields. When these fields are treated quantum-mechanically, we find that even in what is called a vacuum there are 'zero-point' fluctuations, giving 'empty space' an energy that is immensely beyond that contained in what is recognized as matter. In the vacuum state the 'state function' (which represents the whole of space and time) oscillates uniformly at a frequency so high that it is utterly beyond any known physical interpretation. Further, "we would be justified in saying that the vacuum state is, in a certain sense, 'timeless' or 'beyond time,' at least as time is now known, measured and experienced."

With this in mind, it is less than surprising that science is confused about what occurs at the quantum level. For example, L. Beynam, in a paper called "The Emergent Paradigm in Science" that appeared in Revision in 1978, gave a formulation of the wellknown Bell's Theorem. Basic principles of quantum theory spatially separated parts of reality cannot be independent, he goes on to say that this "opens up avenues of scientific development for which the classical constructs of space and time prove almost totally useless and meaningless".

Paul Davies (1988) in God and the New Physics reports on a 1982 experiment by Aspect, Dalibard, and Roger at the Institute of Theoretical and Applied Optics in Paris. From this experiment, this conclusion is drawn:

"Either objective reality does not exist and it is meaningless for us to speak of things or objects as having any reality above and beyond the mind of an observer or faster-than-light communication with the future and the past is possible".

In a recent book called Time--The Familiar Stranger, J.T. Fraser (1987) writes:

"For a photon traveling at the speed of light, the passage of time has no reality. In the "life" of a photon, all events happen at once and all distances shrink to zero.".
Experimental Results Supporting Quantum Brain/Mind/Consciousness

Several published research studies support with empirical data the proposed quantum consciousness model in this paper. In 1993, in the University of Mexico, neurophysiologist Jacobo Grin-bergZylberbaum conducted experiments involving the brain activity of paired students. Two people meditated together with the intention of direct (signal-less, nonlocal) communication. After twenty minutes, they were separated (while still continuing their unifying intention), placed in individual Faraday cages (electromagnetically impervious chambers), and each brain was wired up to an electroencephalogram (EEG) machine. One subject was shown a series of light flashes producing in his or her brain an electrical activity that was recorded in the EEG machine, producing an "evoked potential" extracted by a computer from the brain noise. Surprisingly, the same evoked potential was found to appear in the other subject's brain, and viewable on the EEG of this subject (again minus brain noise). This is called a "transferred potential," but is similar to the evoked potential in phase and strength (GrinbergZylberbaum et al., 1987). This experimented supported the concept that consciousness is nonlocal.

Wackermann, et al. (2003) conducted an experimentwheresixchannelselectroencephalogram (EEG) were recorded simultaneously from pairs of separated human subjects in two acoustically and electromagnetically shielded rooms. The results indicate that correlations between brain activities of two separated subjects may occur, although no biophysical mechanism is known. This also supporting the non-local property of human consciousness.

Persinger, et al. (2010) performed an experiment with magnetic stimulations of the brain in order to recreated non-local correlations. The experiment concluded that the human brain is the focus of all human experiences. The substantial microstructural and neuroelectrical differences between the two cerebral hemispheres predicts two major classes of mystical experiences which involve the sensed presence and the out-of-body experience. Direct cerebral electrical stimulation during the 20th century evoked these experiences.

Persinger, et al. (2003) conducted an 
experiment with four pairs of adult siblings served once as either the stimulus or the response person in two sessions separated by one week. While the brain of the stimulus person, who was seated in a closed chamber, was exposed successively to six different complex magnetic fields for $5 \mathrm{~min}$. each quantitative monopolar electroencephalographic measurements over the frontal, temporal, parietal, and occipital lobes were collected by computer for the response person who was seated in another room. The results suggest that an appropriate altered state of one brain can effect specific predictable frequencies of the electroencephalographic activity of another distant brain which is genetically related also supporting the non-local property of human consciousness.

Early experiments conducted that prove that consciousness is responsible for the collapse of the wave function were criticized mainly because the subjective component that require an individual to state when he or she observes the wave function. Some scientists have argued that is not human consciousness that collapses the wave function but the environment. The 'subjective reduction' interpretation of measurement in quantum physics proposes that the collapse of the wavepacket, associated with measurement, is due to the consciousness of human observers. A refined conceptual replication of an earlier experiment, designed and carried out to test this interpretation in the 1970s, is reported by Bierman (2003). Two improvements are introduced. First, the delay between pre-observation and final observation of the same quantum event is increased from a few microseconds in the original experiment to one second in this replication. Second, rather than using the final observers' verbal response as the dependent variable, his early brain responses as measured by EEG are used. The results confirm the collapse of the wave function but this time not confirmed by verbal confirmation but by EEG measurements in order to avoid the argument of bias and environment as responsible for this phenomenon.

Germine (1998) performed a study, where random and uncertain stimuli are generated by radioactive decay and recorded on two separate disks. These data are observed by a human subject, whereby the data are collapsed in the consciousness of that subject. The same data are later observed by a second subject. It is proposed that there is a cognitive process that occurs when the wavefunction is collapsed, which is manifested in recordings of electrical potential. These electrical-potential changes will occur in the first subject, who is collapsing the unobserved and therefore uncertain data, but not in the second, who is observing collapses and therefore certain data. The two subjects will alternately observe the two data conditions, and a record of the brain-potential difference between the two conditions for each subject will be determined. Any statistical differences observed when all other variables are controlled will relate to brain processes associated with collapse of the wavefunction. Such results supported the hypothesis that the collapse of the wavefunction is a universal mental process.

Another evidence of the non locality of quantum consciousness is proposed by John Lorber (1981) that specialized in children with hydrocephalus, or water on the brain. Children with this condition have an abnormal amount of cerebral spinal fluid accumulation in the cavities inside their brain compressing brain tissue that usually leads to mental retardation seizures, paralysis and blindness and if not treated to death. Lorber describes dozens of children and some adults with severe hydrocephalus but live normal lives. Indeed, in a sample of children with their cerebral space filled with ninety-five percent of spinal fluid in their skull leaving virtually no room for any brain tissue, half of them had a higher IQ than one hundred and thirty.

Penrose and Hameroff (2002) have argued that that the human brain is a quantum computer and that quantum computations occur in the brain materially and literally. More important, it is exactly this kind of quantum computations in the brain that leads to the mind in general and consciousness in particular. Much effort has been taken to pinpoint how quantum computations are carried out neurophysically, for example, through entangled microtubules in neurons connected and synchronized by gap junctions. When entanglement collapses by "orchestrated objective reduction," a fundamental effect of quantum gravity, consciousness arises. Recently, this Orch OR state reduction is linked to the gamma band EEG signal in the brain $(\sim 40 \mathrm{~Hz})$, suggesting a $\sim 25$-ms rhythm of conscious progression.

Hitchcock (2003) a quantum computing model of the brain called T-computer that is in charge of linearizing events in order to create time. T-computers are essential to our maps of reality. They are used to create ordered sets of time labeled observed events or whose 'linear' or non-linear causal time ordering 
may be the location of the infostates representing the events in memory and their contents. An infostate of a system is the set of configuration observables for that system along with the information content usually expressed as the wavefunction for the system. Information originates in quantum system and is processed as quantum or classical states of the neural networks of our brains. The model supports the idea that time is just a sequence of events created by the brain from the quantum reality.

\section{Proposed quantum consciousness model}

The proposed quantum consciousness model has seven statements that are based on the literature review and experimental results discussed in previous sections. The seven proposed statements are:

1. What consciousness is able to perceive with its five senses is not reality. Quantum physics has shown that space and time are illusions of perception. Our body cannot really be a reality if it does not occupy most of the space it seems to occupy, quantum physics revealed that the shape of the interior of an atom is almost entirely empty space and that matter is made of concentrated vibrating energy. Time is also an illusion and it represents a sequence of linear events that the brain generates based on perceived energy around every 25 milliseconds.

2. The model proposes that consciousness is non local and can work independently of the physical brain. Nonlocality or "action at a distance" is the nature of consciousness. Human Consciousness is non-spatial and non-temporal and not in the brain but in prespacetime. Consciousness is multidimensional, it can exist outside the threedimensional reality.

3. The model explains that we live in a collective consciousness that connectsall the consciousnesses of the universe to the supreme consciousness.

4. Consciousness is likely play important roles in quantum effects such as in the wave function collapse, this is the foundation of the reality that we perceive.

5. Conscious intentions likely have physical effects on matter at distance due to the entanglement quantum effect.

6. Materialistic theories for the explanation of consciousness are likely invalid (Neuroscience).

7. Brain is a computer processor and interface between human Consciousness and the external world.

\section{Urantia Book}

The Urantia Book (1996) is a spiritual and philosophical book that originated in Chicago sometime between 1924 and 1955. The authors introduce the word "Urantia" as the name of the planet Earth and state that their intent is to "present enlarged concepts and advanced truth. The book aims to unite religion, science and philosophy, and its enormous amount of material about science is unique among literature claimed to be presented by celestial beings. Among other topics, the book discusses the origin and meaning of life, humankind's place in the universe, the relationship between God and people, and the life of Jesus.

The Urantia Foundation, a U.S.-based non-profit group, first published The Urantia Book in 1955. The book and its publishers do not name a human author. Instead, it is written as if directly presented by numerous celestial beings appointed to the task of providing an "epochal" religious revelation. As early as 1911, William S. Sadler and his wife Lena Sadler, physicians in Chicago and well known in the community, are said to have been approached by a neighbor who was concerned because she would occasionally find her husband in a deep sleep and breathing abnormally (Urantia, 1996).

The Sadlers came to observe the episodes, and over time, the individual produced verbal communications that claimed to be from "student visitor" spiritual beings. This changed sometime in early 1925 with a "voluminous handwritten document," which from then on became the regular method of purported communication. The individual was never identified publicly but has been described as "a hard-boiled business man, member of the board of trade and stock exchange" (Urantia, 1996).

The Sadlers were both respected physicians, and William Sadler was a debunker of paranormal claims, who is portrayed as not believing in the supernatural. In 1929, he published a book called The Mind at Mischief, in which he explained the fraudulent methods of mediums and how self-deception leads to psychic claims (Urantia, 1996).

In 1923, a group of Sadler's friends, former patients, and colleagues began meeting for Sunday philosophical and religious discussions, but became interested in the strange communications when Sadler mentioned the case at their fourth meeting and read samples at their request. Shortly afterwards, a communication reportedly was 
received about which this group would be allowed to devise questions and that answers would be given by celestial beings through the "contact personality". Sadler presented this development to the group, and they generated hundreds of questions without full seriousness, but their claim is that it resulted in the appearance of answers in the form of fully written papers. The Sadlers and others involved, now all deceased, claimed that the papers of the book were physically materialized from 1925 until 1935 in a way that was not understood even by them, with the first two parts being completed in 1934 and the third and fourth in 1935. The last Forum gathering was in 1942 (Urantia, 1996).

After the last of Part IV was obtained in 1935, an additional period of time supposedly took place where requests for clarifications resulted in revisions. Sadler and his son William (Bill) Sadler, Jr. at one point wrote a draft introduction and were told that they could not add their introduction. The Foreword was then "received". The communications purportedly continued for another two decades while members of the Forum studied the book in depth, and according to Sadler and others, permission to publish it was given to them in 1955 (Urantia, 1996).

The Urantia Book is a revelation, a presentation of truth to us, about the Creator and about creation. It greatly expands our view and understanding of the Creator and the cosmos, and with this bigger picture, science, religion, and history, and other areas of human knowledge become integrated. We are not alone in the universe, quite the contrary. The Urantia Book was written by love-respecting, civilized inhabitants of the universe. It was written by a revelatory committee, through a process involving a contact human, for the betterment of our planet. The identity of the contact human is not known, and not considered important. Urantia is the name of our planet (Urantia, 1996).

The Urantia Book revelation is not small; the edition quoted has 2,097 pages of fine print. For most of us, it is not a quick study or easy reading. The Urantia Book is valuable, for it reveals a much larger perspective than was previously known on Earth regarding God, the universe's inhabitants, and the cosmos in which we live. The revelations from the Urantia Book are presented in four parts. Part 1, The Central and Superuniverses, is about God, God's relationship to creation, God's relationship to individuals, and the structure and inhabitants of the greater cosmos. Part 2, The Local Universe, is about our part of the cosmos. It presents topics including creation, evolution, administration, and the various inhabitants of our local universe. Part 3, The History of Urantia, includes information about the origin of our planet, and about its physical, biological, and social evolution. Part 4, The Life and Teachings of Jesus, is self-explanatory (Urantia, 1996).

The Urantia Book is approximately 2,000 pages long, and consists of a body of 196 "papers" divided in four parts, and an introductory forward:

- Part I, titled "The Central and Superuniverses", addresses what the authors consider the highest levels of creation, including the eternal and infinite "Universal Father", his Trinity associates, and the "Isle of Paradise".

- Part II, "The Local Universe", describes the origin, administration, and personalities of the local universe of "Nebadon", the part of the cosmos where Earth resides. It presents narratives on the inhabitants of local universes and their work as it is coordinated with a scheme of spiritual ascension and progression of different orders of beings, including humans, angels, and others.

- Part III, "The History of Urantia", compiles a broad history of the Earth, presenting a purported explanation of the origin, evolution, and destiny of the world and its inhabitants. Topics include Adam and Eve, Melchizedek, essays on the concept of the Thought Adjuster, "Religion in Human Experience", and "Personality Survival".

- Part IV, "The Life and Teachings of Jesus", is the largest part at 775 pages, and is often noted as the most accessible and most impressive, narrating a detailed biography of Jesus that includes his childhood, teenage years, family life, and public ministry, as well as the events that led to his crucifixion, death, and resurrection. Its papers continue about appearances after he rose, Pentecost and, finally, "The Faith of Jesus".

Quantum consciousness model and the Urantia Book

In this section, portions of the Urantia book that support the proposed quantum consciousness model are presented with a brief explanation on how each portion supports the model. Table 1 presents the principle(s) supported by each Urantia book reference with the corresponding explanation. 
Table 1. Urantia book and consciousness model

\begin{tabular}{|c|c|c|c|}
\hline $\begin{array}{l}\text { Quantum } \\
\text { Consciousness model } \\
\text { principle(s) }\end{array}$ & $\begin{array}{l}\text { Urantia book } \\
\text { reference }\end{array}$ & $\begin{array}{l}\text { Quote from the Urantia book that supports } \\
\text { quantum consciousness model principle }\end{array}$ & $\begin{array}{l}\text { Explanation about how the Urantia book } \\
\text { supports the quantum }\end{array}$ \\
\hline 1 & $12: 5.1$ & $\begin{array}{l}\text {... Time comes by virtue of motion and because mind is } \\
\text { inherently aware of sequentiality. ............ }\end{array}$ & $\begin{array}{l}\text { Time is an illusion and it represents a sequence } \\
\text { of linear events that the brain generates from } \\
\text { quantum energy. }\end{array}$ \\
\hline 1 & $12: 5.5$ & $\begin{array}{l}\text { Relationships to time do not exist without motion in } \\
\text { space, but consciousness of time does. Sequentiality can } \\
\text { consciousize time even in the absence of motion. Man's } \\
\text { mind is less time-bound than space-bound because of } \\
\text { the inherent nature of mind. ......... }\end{array}$ & $\begin{array}{l}\text { Time is an illusion and it represents a sequence } \\
\text { of linear events that the brain generates from } \\
\text { quantum energy. }\end{array}$ \\
\hline 1 & $12: 5.7$ & $\begin{array}{l}\text { There are three different levels of time cognizance: } \\
\text { 1. Mind-perceived time - consciousness of sequence, } \\
\text { motion, and a sense of duration. }\end{array}$ & $\begin{array}{l}\text { Time is an illusion and it represents a sequence } \\
\text { of linear events that the brain generates from } \\
\text { quantum energy. }\end{array}$ \\
\hline 2 & $12: 8.7$ & $\begin{array}{l}\text {........the phenomenon of mind, is the exclusive domain } \\
\text { of the Conjoint Actor, who thus becomes the partner } \\
\text { of the spiritual mind, the essence of the morontia } \\
\text { mind, and the substance of the material mind of the } \\
\text { evolutionary creatures of time. }\end{array}$ & $\begin{array}{l}\text { The Conjoint Actor personalizes as an unlimited } \\
\text { spirituality, co-ordinated with absolute mind, } \\
\text { and with prerogatives of energy manipulation. } \\
\text { The mortal intellect, as such, has perished, has } \\
\text { ceased to exist as a focalized universe entity } \\
\text { apart from the undifferentiated mind circuits of } \\
\text { the Creative Spirit. But the meanings and values } \\
\text { of the mortal mind have not perished. Certain } \\
\text { phases of mind are continued in the surviving } \\
\text { soul. } \\
\text { Consciousness is multidimensional, it can exist } \\
\text { outside the three-dimensional reality. }\end{array}$ \\
\hline 1,4 & $12: 8.10$ & $\begin{array}{l}\text { Matter. Organized energy which is subject to linear } \\
\text { gravity except as it is modified by motion and } \\
\text { conditioned by mind. }\end{array}$ & $\begin{array}{l}\text { The book confirms that matter is nothing more } \\
\text { than concentrated energy that is linked to } \\
\text { consciousness. Matter is conditioned by mind. }\end{array}$ \\
\hline 6 & 12:8.11 & $\begin{array}{l}\text { Mind. Organized consciousness which is not wholly } \\
\text { subject to material gravity, and which becomes truly } \\
\text { liberated when modified by spirit. }\end{array}$ & $\begin{array}{l}\text { Materialistic theories for the explanation of } \\
\text { consciousness are likely invalid according to this } \\
\text { statement. True consciousness has no material } \\
\text { origin and it is not subject to the physical laws } \\
\text { of gravity. }\end{array}$ \\
\hline
\end{tabular}

On Paradise the three energies, physical, mindal, and spiritual, are co-ordinate. In the evolutionary cosmos 12:8.14 energy-matter is dominant except in personality, where spirit, through the mediation of mind, is striving for the mastery. ............

In cosmic evolution matter becomes a philosophic shadow cast by mind in the presence of spirit luminosity of divine enlightenment, but this does not invalidate the reality of matter-energy. Mind, matter, and spirit are equally real, but they are not of equal value to personality in the attainment of divinity.

The brighter the shining of the spiritualized personality (the Father in the universe, the fragment of potential spirit personality in the individual creature), the greater the shadow cast by the intervening mind upon its material investment. In time, man's body is just as real as mind or spirit, but in death, both mind (identity) and spirit survive while the body does not. ......

The foundation of the universe is material in the sense that energy is the basis of all existence, and pure energy is controlled by the Universal Father. .........

Space potency is a prereality; it is the domain of the Unqualified Absolute and is responsive only to the personal grasp of the Universal Father,

The quantity of energy taken in or given out when electronic or other positions are shifted is always a " quantum " or some multiple thereof, but the vibratory or wavelike behavior of such units of energy is wholly determined by the dimensions of the material structures concerned.
The true essence of consciousness is not material.

Matter is the product of consciousness, real but not of equal value in the evolution of spirit.

Consciousness is non local and can work independently of the physical brain as it survives mortal death. Consciousness is connected to the supreme consciousness due to the fragment that indwell in the individual True consciousness is non material as it does not die with mortal death. Matter is a creation of the mind.

Matter is made of concentrated vibrating energy.

Space potency is the source of energy for the creation of reality (prereality). All material reality is created from this source and molded by consciousness.

Matter is made of concentrated vibrating energy 


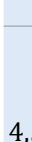

Paradise mind is beyond human understanding; it is existential, nonspatial, and nontemporal. .......

In the evaluation and recognition of mind it should be remembered that the universe is neither mechanical nor magical; it is a creation of mind and a mechanism of law. ......

On a material world you think of a body as having a spirit, but we regard the spirit as having a body. The material eyes are truly the windows of the spirit-born soul. The spirit is the architect, the mind is the builder, the body is the material building.

The spirit is the creative reality; the physical counterpart is the time-space reflection of the spirit reality, the physical repercussion of the creative action of spirit-mind.

Position status. Personality functions equally efficiently in the local universe, in the superuniverse, and in the central universe.

.....individual members are not connected with each other except in relation to the whole and through the individuality of the whole.

.........Jesus gave qualified approval of some of the Greek teachings which had to do with the theory that the material things of the world are shadowy reflections of invisible but more substantial spiritual realities, he sought to lay a more trustworthy foundation for the lad's thinking; so he began a long dissertation concerning the nature of reality in the universe.

A one-eyed person can never hope to visualize depth of perspective. Neither can single-eyed material scientists nor single-eyed spiritual mystics and allegorists correctly visualize and adequately comprehend the true depths of universe reality. ......

Knowledge is the sphere of the material or factdiscerning mind. Truth is the domain of the spiritually endowed intellect that is conscious of knowing God. Knowledge is demonstrable; truth is experienced. Knowledge is a possession of the mind; truth an experience of the soul, the progressing self. Knowledge is a function of the nonspiritual level; truth is a phase of the mind-spirit level of the universes. The eye of the material mind perceives a world of factual knowledge the eye of the spiritualized intellect discerns a world of true values. These two views, synchronized and harmonized, reveal the world of reality, wherein wisdom interprets the phenomena of the universe in terms of progressive personal experience.

Time is the stream of flowing temporal events perceived Time is also an illusion and it represents by creature consciousness. Time is a name given to the a sequence of linear events that the brain succession-arrangement whereby events are recognized generates based on perceived energy around and segregated. .......

Animals do not sense time as does man, and even to man, because of his sectional and circumscribed view, time appears as a succession of events; but as man ascends, as he progresses inward, the enlarging view of this event procession is such that it is discerned more and more in its wholeness. That which formerly appeared as a succession of events then will be viewed as a whole and perfectly related cycle; in this way will circular simultaneity increasingly displace the onetime consciousness of the linear sequence of events.
Human Consciousness is non-spatial and non-temporal and not in the brain but in prespacetime

Consciousness is likely play important roles in quantum effects such as in the wave function collapse, this is the foundation of the reality that we perceive. Conscious intentions likely have physical effects on matter at distance due to the entanglement quantum effect.

Brain is a computer processor and interface between human Consciousness and the external world. The brain are the eyes of consciousness.

Consciousness is likely play important roles in quantum effects such as in the wave function collapse, this is the foundation of the reality that we perceive. Conscious intentions likely have physical effects on matter at distance due to the entanglement quantum effect.

Consciousness is multidimensional, it can exist outside the three-dimensional reality.

The model explains that we live in a collective consciousness that connects all the consciousnesses of the universe to the supreme consciousness.

Consciousness is likely play important roles in quantum effects such as in the wave function collapse, this is the foundation of the reality that we perceive.

Materialistic theories for the explanation of consciousness are likely invalid (Neuroscience). Consciousness understating requires a spiritual and materialistic views.

Brain is a computer processor and interface between human Consciousness. and the external world. Fact is the domain of the brain but the truth is the domain of consciousness. every 25 milliseconds.

Time is also an illusion and it represents a sequence of linear events that the brain generates based on perceived energy around every 25 milliseconds. There is no past or future but only a constant present. 
There are seven different conceptions of space as it is conditioned by time. Space is measured by time, not time by space. The confusion of the scientist grows out of failure to recognize the reality of space. Space is not merely an intellectual concept of the variation in relatedness of universe objects. Space is not empty, and the only thing man knows which can even partially transcend space is mind. Mind can function independently of the concept of the spacerelatedness of material objects. Space is relatively and comparatively finite to all beings of creature status. ....

The time-space concept of a mind of material origin is destined to undergo successive enlargements as the conscious and conceiving personality ascends the levels of the universes. When man attains the mind intervening between the material and the spiritual planes of existence, his ideas of time-space will be enormously expanded both as to quality of perception and quantity of experience. .......the time-space concept will increasingly approximate the timeless and spaceless concepts of the Absolutes.

On the levels of the infinite and the absolute the moment of the present contains all of the past as well as all of the future. I AM signifies also I WAS and I WILL $B E$. And this represents our best concept of eternity and the eternal.

Only by ubiquity could Deity unify time-space manifestations to the finite conception, for time is a succession of instants while space is a system of associated points. You do, after all, perceive time by analysis and space by synthesis. You co-ordinate and associate these two dissimilar conceptions by the integrating insight of personality. Of all the animal world only man possesses this time-space perceptibility. To an animal, motion has a meaning, but motion exhibits value only to a creature of personality status.

Space comes the nearest of all nonabsolute things to being absolute. Space is apparently absolutely ultimate. The real difficulty we have in understanding space on the material level is due to the fact that, while material bodies exist in space, space also exists in these same material bodies. While there is much about space that is absolute, that does not mean that space is absolute.

It may help to an understanding of space relationships if you would conjecture that, relatively speaking, space is after all a property of all material bodies. Hence, when a body moves through space, it also takes all its properties with it, even the space which is in and of such a moving body.

All patterns of reality occupy space on the material levels, but spirit patterns only exist in relation to space; they do not occupy or displace space, neither do they contain it. .......
What consciousness is able to perceive with its five senses is not reality. Quantum physics has shown that space and time are illusions of perception.

The model proposes that consciousness is non local and can work independently of the physical brain.

Time is also an illusion and it represents a sequence of linear events that the brain generates based on perceived energy around every 25 milliseconds. There is no future or past but just a constant present.

What consciousness is able to perceive with its five senses is not reality. Quantum physics has shown that space and time are illusions of perception.

What consciousness is able to perceive with its five senses is not reality. Quantum physics has shown that space and time are illusions of perception. Our body cannot really be a reality if it does not occupy most of the space it seems to occupy, quantum physics revealed that the shape of the interior of an atom is almost entirely empty space and that matter is made of concentrated vibrating energy.

What consciousness is able to perceive with its five senses is not reality. Quantum physics has shown that space and time are illusions of perception. Our body cannot really be a reality if it does not occupy most of the space it seems to occupy, quantum physics revealed that the shape of the interior of an atom is almost entirely empty space....

What consciousness is able to perceive with its five senses is not reality. Quantum physics has shown that space and time are illusions of perception. Our body cannot really be a reality if it does not occupy most of the space it seems to occupy, quantum physics revealed that the shape of the interior of an atom is almost entirely empty space and that matter is made of concentrated vibrating energy. 


\begin{tabular}{|c|c|c|c|}
\hline 6,7 & 118:8.2 & $\begin{array}{l}\text { Mortal man is a machine, a living mechanism; his } \\
\text { roots are truly in the physical world of energy. Many } \\
\text { human reactions are mechanical in nature; much of life } \\
\text { is machinelike. But man, a mechanism, is much more } \\
\text { than a machine; he is mind endowed and spirit indwelt; } \\
\text { and though he can never throughout his material life } \\
\text { escape the chemical and electrical mechanics of his } \\
\text { existence, he can increasingly learn how to subordinate } \\
\text { this physical-life machine to the directive wisdom of } \\
\text { experience by the process of consecrating the human } \\
\text { mind to the execution of the spiritual urges of the } \\
\text { indwelling Thought Adjuster. }\end{array}$ & $\begin{array}{l}\text { Materialistic theories for the explanation of } \\
\text { consciousness are likely invalid (Neuroscience). } \\
\text { Brain is a computer processor and interface } \\
\text { between human Consciousness and the external } \\
\text { world. }\end{array}$ \\
\hline 3 & 118:9.4 & $\begin{array}{l}\text { The grand universe is mechanism as well as organism, } \\
\text { mechanical and living-a living mechanism activated by } \\
\text { a Supreme Mind, co-ordinating with a Supreme Spirit, } \\
\text { and finding expression on maximum levels of power } \\
\text { and personality unification as the Supreme Being. But } \\
\text { to deny the mechanism of the finite creation is to deny } \\
\text { fact and to disregard reality. }\end{array}$ & $\begin{array}{l}\text { The model explains that we live in a } \\
\text { collective consciousness that connects all the } \\
\text { consciousnesses of the universe to the supreme } \\
\text { consciousness. }\end{array}$ \\
\hline 6 & 118:10.13 & $\begin{array}{l}\text {.....As long as men measure only by the yardstick of the } \\
\text { things of a physical nature, they can never hope to find } \\
\text { unity in time and space. }\end{array}$ & $\begin{array}{l}\text { Materialistic theories for the explanation of } \\
\text { consciousness are likely invalid (Neuroscience). }\end{array}$ \\
\hline 4 & $16: 9.1$ & $\begin{array}{l}\text {...personal creature possesses innate recognition- } \\
\text { realization of energy reality, mind reality, and spirit } \\
\text { reality. ....Aside from these three inalienables of human } \\
\text { consciousness, all human experience is really subjective } \\
\text { except that intuitive realization of validity attaches to } \\
\text { the unification of these three universe reality responses } \\
\text { of cosmic recognition. }\end{array}$ & $\begin{array}{l}\text { Consciousness is likely play important roles in } \\
\text { quantum effects such as in the wave function } \\
\text { collapse, this is the foundation of the reality that } \\
\text { we perceive. }\end{array}$ \\
\hline 2 & $16: 9.3$ & $\begin{array}{l}\text { If mortal man fails to survive natural death, the real } \\
\text { spiritual values of his human experience survive as } \\
\text { a part of the continuing experience of the Thought } \\
\text { Adjuster. ........ }\end{array}$ & $\begin{array}{l}\text { The model proposes that consciousness is } \\
\text { non local and can work independently of the } \\
\text { physical brain. }\end{array}$ \\
\hline
\end{tabular}

\section{Conclusions}

In this article, a quantum consciousness model with seven principles is proposed and supported with literature review and experimental results from published literature. The Urantia book is introduced as a revelation that aims to unite religion, science and philosophy. The Urantia book reveals the nature of human consciousness and supports with its theology the proposed quantum consciousness model. The article introduces the Urantia book as a source of knowledge that has the intention to reconciliate religion paradigms with consciousness studies. Future research would be focused in expanding the proposed quantum consciousness model with the help of the Urantia book and modern research in consciousness and quantum physics.

\section{References}

Beynam Laurence M. "The Emergent Paradigm in Science," Revision, Spring, 1978.

Bierman JB. Does consciousness collapse the wave-packet?. Mind \& Matter, 2003; 1(1): 45-77

Bohm D. Wholeness and the Implicate Order. London: Routledge and Kegan Paul, 1980.

Davies P. The Cosmic Blueprint. New York: Simon and Schuster, 1988.
Fraser JT. Time, the familiar stranger. Univ of Massachusetts Press, 1987.

Germine M. Experimental Model for Collapse of the Wavefunction. Dynamical Psychology, 1998.

Greyson B and Stevenson I. The phenomenology of near-death experiences. The American journal of psychiatry, 1980.

Griffin DR (Editor) Physics and the Ultimate Significance of Time. Albany: State University of New York Press, 1986.

Grinberg-Zylberbaum Jand Ramos J. Patterns of interhemispheric correlation during human communication. International Journal of Neuroscience, 1987; 36: 41-53.

Hameroff Stuart. "Quantum computation in brain microtubules? The Penrose-Hameroff'Orch OR'model of consciousness." Philosophical Transactions-Royal Society of London Series A Mathematical Physical and Engineering Sciences.

Hitchcock SM. T-computers and the Origins of Time in the Brain. NeuroQuantology, 2003;1(4).

$\mathrm{Hu} \mathrm{H}$ and $\mathrm{Wu}$ M. Current landscape and future direction of theoretical \& experimental quantum brain/mind/ consciousness research. Journal of Consciousness Exploration \& Research, 2010; 1(8).

$\mathrm{Hu} \mathrm{H}$ and Wu M. The Relationship between Human Consciousness \& Universal Consciousness. Scientific GOD Journal, 2013; $4(3)$.

Lorber J. Is your brain really necessary?. Nursing mirror, 1981; 152(18): 29-30. 
Marshall I and Zohar D. Who's afraid of Schrödinger's cat. New York: 1997, Quill/William Morrow.

Mullins L and Sprunger MJ. A History of the URANTIA Papers (p. 5). Boulder, CO: Penumbra Press, 2000.

Persinger MA, Koren SA, Tsang EW. Enhanced power within a specific band of theta activity in one person while another receives circumcerebral pulsed magnetic fields: a mechanism for cognitive influence at a distance?. Perceptual and Motor Skills, 2003; 97(3): 877-94.

Persinger MA, Saroka KS, Koren SA, St-Pierre LS. The electromagnetic induction of mystical and altered states within the laboratory. Journal of Consciousness Exploration \& Research, 2010; 1(7): 808-30

Russell RJ, Murphy N, Isham CJ. Quantum cosmology and the laws of nature: scientific perspectives on divine action. 1993.
The Urantia Book. Uversa Press, Chicago, 1996.

Valverde R. Possible Role of Quantum Physics in Transpersonal \& Metaphysical Psychology. Journal of Consciousness Exploration \& Research, 2015a; 7(4): 303-09.

Valverde R. Channeling as an Altered State of Consciousness in Transpersonal Psychology Therapy. Journal of Consciousness Exploration \& Research, 2015b; 6(7).

Valverde R. A Quantum Biofeedback and Neurotechnology Cybertherapy System for the Support of Transpersonal Psychotherapy. NeuroQuantology, 2016; 14(4).

Wackermann J, Seiter C, Keibel H, Walach H. Correlations between brain electrical activities of two spatially separated human subjects. NeuroScience letters, 2003; 336(1): 60-64.

Wolf Fred Alan. Star Wave. New York: Macmillan, 1984. 